\title{
Metabolic Syndrome and Cognition: Follow-Up Study of Chinese Over-55-Year-Olds
}

\author{
Paulina Maria Przybycien-Gaweda Xinyi Gwee Qi Gao Denise Qian Ling Chua \\ Johnson Fam Tze Pin Ng
}

Department of Psychological Medicine, Gerontology Research Programme, National University of Singapore, Singapore, Singapore

\section{Keywords}

Metabolic syndrome $\cdot$ Cognition $\cdot$ Cognitive domains

\begin{abstract}
Background/Aim: Studies of the associations of the metabolic syndrome (MetS) with cognitive function and decline are inconclusive. We investigated the associations of the MetS with cognitive functions in 823 Chinese $>55$-year-olds followed up over 4.5 years. Methods: The relationships between the MetS and baseline and follow-up $z$-scores of cognitive domain functions were examined using mixed model analysis. Results: There were specific inverse cross-sectional associations of single cardiometabolic risk factors with cognition, such as hyperglycemia with processing speed ( $p=$ 0.045 ). The MetS was negatively associated with 3 out of 4 cognitive domains ( $p=0.018$ to $p=0.003)$, and the count of cardiometabolic risk factors with all cognitive domains ( $p=$ 0.025 to $p=0.002$ ). Longitudinally, dyslipidemia was associated with worse decline in memory and learning $(p=0.022)$. The count of cardiometabolic risk factors was associated with worse declines in cognition ( $p=0.032$ for global cognition). Conclusion: Among middle-aged and older Asians, an increased number of component cardiometabolic risk factors of the MetS was associated with a worse decline in cognitive function over time.

(c) 2020 S. Karger AG, Basel
\end{abstract}

\section{Introduction}

The metabolic syndrome (MetS), defined as the cooccurrence of at least 3 out of 5 cardiometabolic risk factors (abdominal adiposity, hyperglycemia, hypertriglyceridemia, lowered high-density lipoprotein cholesterol [HDL-C] and hypertension) [1] is known to significantly increase the risk of cardiovascular disease, type 2 diabetes and stroke [2-4]. Many studies have investigated the roles of individual cardiometabolic risk factors in the development and progression of dementia, mild cognitive impairment (MCI) and cognitive decline [5-8]. Studies of the associations of the MetS and its components with cognitive function and decline among nondemented older individuals are inconclusive and based on inconsistent data [9].

A recent systematic review of 25 studies included a majority of cross-sectional studies, and the fewer longitudinal studies presented conflicting results. Only hyperglycemia among the other vascular risk factors was most consistently associated with poor cognitive abilities and with MCI prevalence. A number of prospective studies have reported that the MetS is associated with declines in cognitive functions over time, mostly based on MMSE (Mini-Mental State Examination) global cognition, but those findings are inconsistent [10-25]. The heteroge- karger@karger.com

(C) 2020 S. Karger AG, Basel

www.karger.com/dem

Karger ${ }^{\prime}=$
Tze Pin Ng

Department of Psychological Medicine

National University of Singapore, NUHS Tower Block Level 9

1E Kent Ridge Road, Singapore 119228 (Singapore)

pcmngtp@nus.edu.sg 
neous findings may be partly explained by the differential effects at younger and older ages. The MetS was found to be associated with cognitive decline in $\leq 70$-year-olds, but not in $>70$-year-olds, [10] supporting the general view that the overall prognostic value of the MetS in very old persons is not greater than that of the single risk factors taken separately [26].

Few longitudinal studies have investigated comprehensively specific domains of cognition that are potentially affected by the MetS in a young-old nondemented population cohort. This study examines the associations of the MetS with impairment in neurocognitive domains at baseline and over time in a prospective cohort of Chinese participants aged over 55 years in the Singapore Longitudinal Aging Study (SLAS) who were followed up for a mean of 4.5 years.

\section{Subjects and Methods}

\section{Study Design and Population}

The SLAS is a population-based study of ageing and health in middle-aged and older adults in Singapore. In the first-wave recruitment cohort (SLAS-1), 2,804 older adults aged $\geq 55$ years were recruited in 2003/2004 and followed up from January 1, 2006, to December 31, 2009. The mean length of follow-up was 4.5 years (range 2.54-4.79, median 3.8). Details on the population sampling and measurements have been described elsewhere [27]. In brief, at recruitment, structured questionnaire interviews, blood sampling, physical and functional testing and clinical assessment collected an extensive range of socioeconomic, lifestyle, psychological, behavioral and physiological data. They included domain-specific neurocognitive assessment (NCA) performed using a comprehensive battery of tests administered to a one-in-three random sub-sample of the participants. The present study used NCA data from 823 nondemented (cognitively normal or diagnosed with MCI) Chinese participants with available baseline data on the MetS and health-related lifestyle variables. The mean age of the study population was 65.3 years ( $\mathrm{SD} \pm 7.2$ ); $62.6 \%$ (515) of the participants were women. The baseline numbers of participants, as well as the numbers among them who had available NCA scores, are shown in Table 1.

\section{Measurements}

Clinical measurements were obtained from self-reports of diagnosis and/or treatments for diabetes mellitus, hypertension, dyslipidemia, cardiovascular disease and stroke, with details on drug use ascertained by inspection of the medication packages. Waist circumference was measured in centimeters at the midpoint between the lowest rib margin and the top of the iliac crest at minimal respiration to the closest $0.1 \mathrm{~cm}$. Blood pressure was determined by the mean of 3 readings with the participants seated, recorded using a standard mercury sphygmomanometer. Blood glucose, triglycerides and HDL-C were derived from overnight fasting serum samples analyzed for blood glucose and the lipid profile using standard laboratory techniques.

\section{Metabolic Syndrome}

The MetS was defined according to NCEP ATP III criteria [1] as the coexistence of $\geq 3$ of the following 5 clinical criteria: large waist circumference ( $\geq 100 \mathrm{~cm}$ in men, $\geq 90 \mathrm{~cm}$ in women), high triglycerides $(\geq 1.7 \mathrm{mmol} / \mathrm{L}$ or receiving drug treatment for high triglycerides), low HDL-C ( $<1.03 \mathrm{mmol} / \mathrm{L}$ in $\mathrm{men},<1.3 \mathrm{mmol} / \mathrm{L}$ in women, or receiving drug treatment for low HDL-C), high blood pressure ( $\geq 130 \mathrm{~mm} \mathrm{Hg}$ systolic, $\geq 85 \mathrm{~mm} \mathrm{Hg}$ diastolic blood pressure, or receiving antihypertensive medication) and high fasting glucose $(\geq 5.6$ $\mathrm{mmol} / \mathrm{L}$ or receiving drug treatment for high glucose).

\section{Neurocognitive Assessment}

Neurocognitive domain performance was assessed by $z$-scores derived from principal component analysis of scores obtained from various cognitive domain tests: (1) processing speed (Trail Making Test, Symbol Digit Modalities Test, Design Fluency), (2) attention/working memory (Digit Span Forward and Backward, Trail Making Test-A, Categorical Verbal Fluency-Animals), (3) executive function (Symbol Digit Modalities Test, Block Design, Design Fluency [D-KEFS], Categorical Verbal Fluency-Animals, Visual Reproduction) and (4) memory and learning (Rey Auditory Verbal Learning Test Immediate and Delayed Recall, Visual Reproduction Immediate and Delayed Recall). The global NCA score was derived by obtaining the composite mean $z$-scores of the domain-specific $z$-scores. The assessment was administered by trained psychology research assistants in the participants' habitual language: English, Mandarin, or Chinese dialects. The details of the neuropsychological tests used in this study and their normative values have been described previously [28].

\section{Covariates}

To control for confounding, known risk factors that are strongly associated with the risk of MCI and dementia were included as covariates in the analyses: age, sex, education (none or $\geq 1$ year of schooling), APOE- $\varepsilon 4$ genotype, smoking status at baseline, daily alcohol consumption, Geriatric Depression Scale (GDS) score $\geq 5$, cardiovascular disease and stroke, and other cardiometabolic risk factors as appropriate. The level of leisure time activity (by tertile) was determined by the summed scores of the number and frequencies (5-point Likert scale) of participation in 18 different categories of physical, social and productive activities [29].

\section{Statistical Analysis}

Differences between MetS groups on cognitive test performance over time were assessed using linear mixed-effects regression models, which assume missing at random values driven by variables included in the analyses, and account for correlations between the repeated measures for each participant. Fixed effect terms model the mean trajectory of participants as a function of covariates, and random effect terms allow individual participants' baseline performance (intercept) and rate of change (slope) to vary randomly about the mean trajectory defined by the fixed effect terms. We examined the effects of "MetS group" and "time" and a "group $\times$ time" interaction, where the interaction terms of MetS group and time indicated group differences in cognitive performance trajectories. The adjusted models included the confounding covariates, as described above. All statistical significance tests were two-sided, and an a level of 0.05 was considered significant. Data analysis was performed using statistical software (SPSS version 22; IBM Corporation). 
Table 1. Baseline risk factors of the participants according to MetS status

\begin{tabular}{|c|c|c|c|c|}
\hline & All participants & MetS & No MetS & $p$ value \\
\hline Number of participants & 823 & 223 & 600 & \\
\hline Number of MetS components & $1.76 \pm 1.10$ & $3.20 \pm 0.40$ & $1.22 \pm 0.75$ & \\
\hline High waist circumference & $45.6(375)$ & $85.7(191)$ & $30.7(184)$ & \\
\hline Glucose abnormality & $16.6(137)$ & $48.9(109)$ & $4.7(28)$ & \\
\hline High blood pressure & $55.5(457)$ & $94.6(211)$ & $41.0(246)$ & \\
\hline Lipid abnormality & $58.0(477)$ & $90.6(202)$ & $45.8(275)$ & \\
\hline Age, years & $65.3 \pm 7.2$ & $67.1 \pm 7.0$ & $64.9 \pm 7.2$ & 0.000 \\
\hline Female sex & $62.6(515)$ & $64.1(143)$ & $62.0(372)$ & 0.575 \\
\hline Nil education & $19.4(160)$ & $28.3(63)$ & $16.2(97)$ & 0.000 \\
\hline APOE- $\varepsilon 4$ & $15.6(128)$ & $13.0(29)$ & $16.5(99)$ & 0.219 \\
\hline \multicolumn{5}{|l|}{ Smoking } \\
\hline Ex-smoker & $9.2(76)$ & $10.3(23)$ & $8.8(43)$ & \\
\hline Current smoker & $6.4(53)$ & $4.5(10)$ & $7.2(43)$ & 0.327 \\
\hline Daily alcohol drinking & $9.4(77)$ & $7.6(17)$ & $10.0(60)$ & 0.298 \\
\hline \multicolumn{5}{|l|}{ Leisure time activity } \\
\hline Lowest tertile & $35.0(288)$ & $39.0(87)$ & $33.5(201)$ & \\
\hline Middle tertile & $36.2(298)$ & $39.5(88)$ & $35.0(210)$ & \\
\hline Upper tertile & $28.8(237)$ & $21.5(48)$ & $31.5(189)$ & 0.019 \\
\hline Cardiac disease & $9.7(80)$ & $19.3(43)$ & $6.2(37)$ & 0.000 \\
\hline Stroke & $2.8(23)$ & $4.9(11)$ & $2.0(12)$ & 0.023 \\
\hline Geriatric Depression Scale score $\geq 5$ & $15.1(124)$ & $15.2(34)$ & $15.0(90)$ & 0.930 \\
\hline
\end{tabular}

Values denote the mean \pm SD or $\%(n)$. The MetS was diagnosed using the NCEP ATP III criteria: participant fulfills $\geq 3$ of the following 5 clinical criteria: large waist circumference ( $\geq 100 \mathrm{~cm}$ in men, $\geq 90 \mathrm{~cm}$ in women), high triglycerides $(\geq 1.7 \mathrm{mmol} / \mathrm{L}[150 \mathrm{mg} / \mathrm{dL}]$ or receiving drug treatment for high triglycerides), low HDL-C $(<1.03$ $\mathrm{mmol} / \mathrm{L}[40 \mathrm{mg} / \mathrm{dL}]$ in $\mathrm{men},<1.3 \mathrm{mmol} / \mathrm{L}[50 \mathrm{mg} / \mathrm{dL}]$ in women, or receiving drug treatment for low HDL-C), high blood pressure ( $\geq 130 \mathrm{~mm} \mathrm{Hg}$ systolic blood pressure, $\geq 85 \mathrm{~mm} \mathrm{Hg}$ diastolic blood pressure, or receiving antihypertensive medication), and high fasting glucose $(\geq 5.6 \mathrm{mmol} / \mathrm{L}[100 \mathrm{mg} / \mathrm{dL}]$ or receiving drug treatment for high glucose). MetS, metabolic syndrome; HDL-C, high-density lipoprotein cholesterol.

\section{Results}

At baseline, 27\% (223) of all participants (823) fulfilled the NCEP ATP III criteria for the MetS. On average, they had 3.2 ( $\mathrm{SD} \pm 0.4$ ) components of the MetS, whereas those with no MetS had $1.22(\mathrm{SD} \pm 0.75)$ components (Table 1). The most common components of the MetS were high blood pressure (94.6\%), followed by dyslipidemia (90.6\%), high waist circumference (85.7\%) and high fasting glucose $(48.9 \%)$.

The baseline profile of the risk factors of the participants according to MetS status is shown in Table 1. Compared to the participants with no MetS, those with the MetS were older and less educated, had significantly lower scores on leisure activity, and expectedly had a higher prevalence of cardiac disease and stroke, but they did not differ regarding sex, smoking, alcohol use, APOE- $\varepsilon 4$ status or depressive symptoms.

The associations between MetS and cognitive test scores are shown without controlling for confounding factors in Table 2. At baseline, MetS was associated with lower processing speed ( $z$-score -0.19 vs. $0.07, p=0.001$ ), executive function $(z$-score -0.20 vs. $0.08, p<0.001)$ and memory and learning $(z$-score -0.17 vs. $0.06, p=0.003)$.

At follow-up, participants with the MetS compared to those with no MetS had significantly lower processing speed ( $z$-score -0.26 vs. $0.07, p=0.026$ ), attention/working memory ( $z$-score -0.26 vs. $0.07, p=0.024)$, executive function $(z$-score -0.27 vs. $0.08, p=0.02)$, memory and learning ( $z$-score -0.37 vs. $0.10, p=0.001)$ and NCA global cognition $(z$-score -0.29 vs. $0.08, p=0.006)$ (Table 2$)$.

\section{MetS and Cognition}

In Table 3 and Figure 1, the results of the linear mixed model of MetS status (and components) at baseline, time and interaction between MetS and time are shown for ease of interpretation as the adjusted estimates of cognitive performance scores at baseline and follow-up, controlling for the confounding factors. Also shown are the results of the significance tests of the 
Table 2. Measurements of baseline and follow-up cognitive performance of the SLAS participants by metabolic syndrome (MetS)

\begin{tabular}{|c|c|c|c|c|c|c|}
\hline & \multicolumn{2}{|c|}{ Baseline } & \multirow[t]{2}{*}{$p$ value } & \multicolumn{2}{|c|}{ Follow-up } & \multirow[t]{2}{*}{$p$ value } \\
\hline & $n$ & mean $\pm \mathrm{SD}$ & & $n$ & mean $\pm S D$ & \\
\hline \multicolumn{7}{|c|}{ Processing speed } \\
\hline All & 823 & $0.00 \pm 1.00$ & & 262 & $0.00 \pm 1.00$ & \\
\hline MetS & 223 & $-0.19 \pm 1.05$ & & 57 & $-0.26 \pm 1.11$ & \\
\hline No MetS & 600 & $0.07 \pm 0.97$ & 0.001 & 205 & $0.07 \pm 0.96$ & 0.026 \\
\hline \multicolumn{7}{|c|}{ Working memory } \\
\hline All & 823 & $0.00 \pm 1.00$ & & 262 & $0.00 \pm 1.00$ & \\
\hline MetS & 223 & $-0.10 \pm 0.99$ & & 57 & $-0.26 \pm 1.10$ & \\
\hline No MetS & 600 & $0.04 \pm 1.00$ & 0.080 & 205 & $0.07 \pm 0.96$ & 0.024 \\
\hline \multicolumn{7}{|c|}{ Executive function } \\
\hline All & 823 & $0.00 \pm 1.00$ & & 262 & $0.00 \pm 1.00$ & \\
\hline MetS & 223 & $-0.20 \pm 0.95$ & & 57 & $-0.27 \pm 0.95$ & \\
\hline No MetS & 600 & $0.08 \pm 1.01$ & 0.000 & 205 & $0.08 \pm 1.00$ & 0.020 \\
\hline \multicolumn{7}{|c|}{ Memory and learning } \\
\hline All & 823 & $0.00 \pm 1.00$ & & 262 & $0.00 \pm 1.00$ & \\
\hline MetS & 223 & $-0.17 \pm 0.92$ & & 57 & $-0.37 \pm 1.06$ & \\
\hline No MetS & 600 & $0.06 \pm 1.02$ & 0.003 & 205 & $0.10 \pm 0.96$ & 0.001 \\
\hline \multicolumn{7}{|l|}{ Global } \\
\hline All & 823 & $0.12 \pm 0.89$ & & 262 & $0.00 \pm 0.90$ & \\
\hline MetS & 223 & $0.03 \pm 1.01$ & & 57 & $-0.29 \pm 0.94$ & \\
\hline No MetS & 600 & $0.14 \pm 0.86$ & 0.412 & 205 & $0.08 \pm 0.87$ & 0.006 \\
\hline
\end{tabular}

parameter estimate for group effect (representing the cross-sectional effect of MetS on cognitive function at baseline), the parameter estimate for time effect (showing the change in cognition scores over time for the whole population), and the parameter estimate for the interaction between MetS and time (showing the change in cognition over time associated with MetS). The models are repeated for each individual MetS component (Table 3).

After adjustment, a significant negative cross-sectional association remained between MetS and processing speed, executive function, and memory and learning. There were trends towards greater cognitive domain performance decline among the participants with the MetS; however, those did not reach significance levels.

\section{MetS Components and Cognition}

A number of MetS components in isolation were significantly associated with lower scores in various neurocognitive domains. Large waist circumference was associated with lower executive function; glucose abnormality with lower processing speed; and high blood pressure with lower processing speed and with poorer attention/ working memory as well as executive function.
Dyslipidemia compared with no dyslipidemia was associated with a significantly worse longitudinal decline in memory and learning (group $\times$ time interaction, $p=0.022$ ). There were trends for other MetS components that were associated with worse cognitive performance declines, but they failed to reach statistical significance.

\section{Number of MetS Components and Cognition}

Table 4 shows the results of the models repeated for the number of MetS components (0-5). The number of MetS components possessed by each study participant had a significant negative cross-sectional association with processing speed (between-group $p=0.008$ ), attention/working memory (between-group $p=0.025$ ), executive function (between-group $p=0.004$ ), and memory and learning (between-group $p=0.002$ ), as well as with worse decline in attention/working memory (group $x$ time $p=0.039$ ), memory and learning (group $\times$ time $p=$ 0.011 ), and global cognition score (group $\times$ time $p=$ 0.032). The estimated effect of having 4 MetS components on global cognition was equivalent to an additional 14 years of age. 
Table 3. Adjusted estimates of cognitive performance scores at baseline and follow-up associated with MetS and components in mixed model analyses

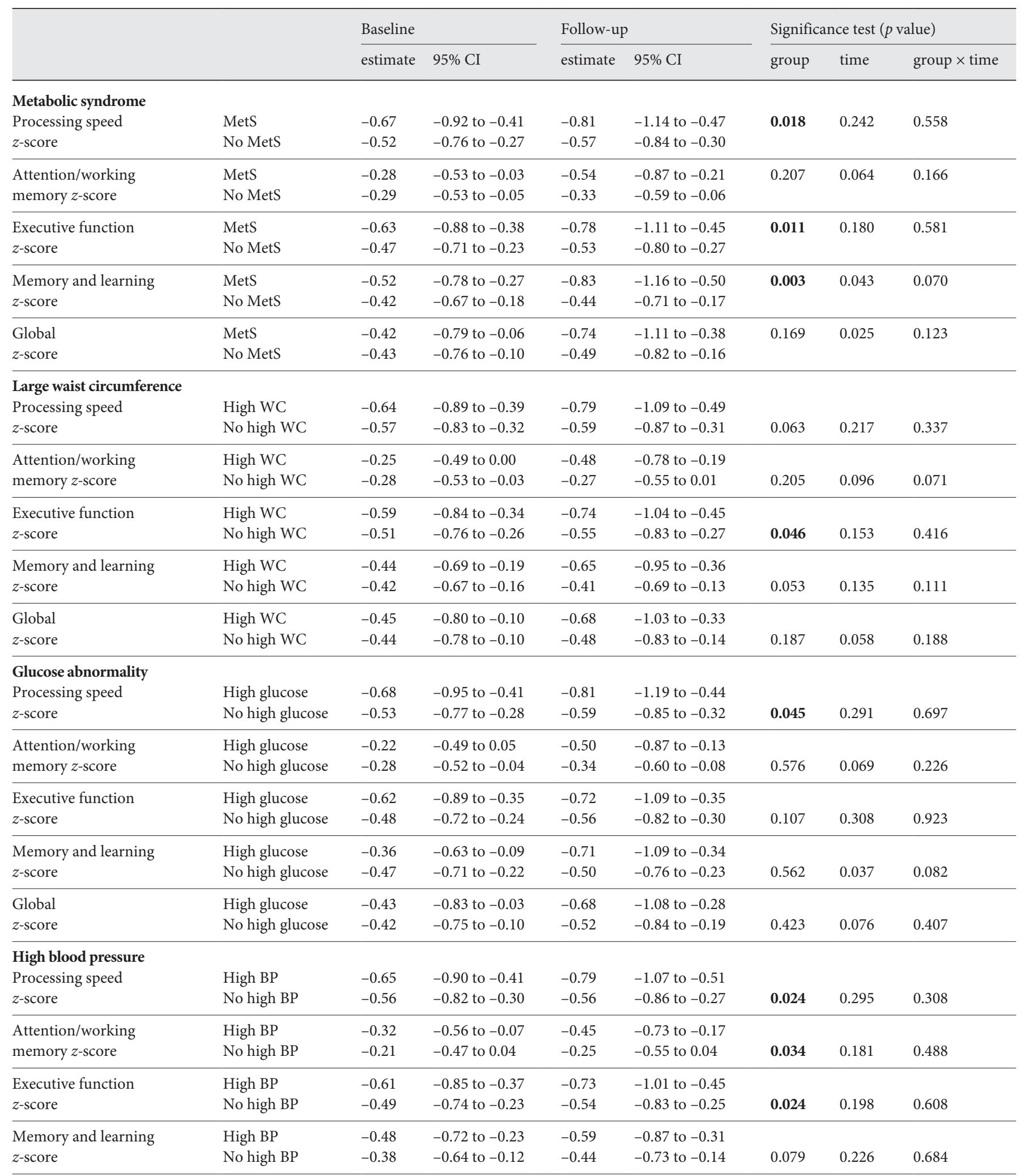


Table 3 (continued)

\begin{tabular}{|c|c|c|c|c|c|c|c|c|}
\hline & & \multicolumn{2}{|l|}{ Baseline } & \multicolumn{2}{|c|}{ Follow-up } & \multicolumn{3}{|c|}{ Significance test ( $p$ value) } \\
\hline $\begin{array}{l}\text { Lipid abnormalities } \\
\text { Processing speed } \\
z \text {-score }\end{array}$ & $\begin{array}{l}\text { Dyslipidemia } \\
\text { No dyslipidemia }\end{array}$ & $\begin{array}{l}-0.54 \\
-0.68\end{array}$ & $\begin{array}{l}-0.79 \text { to }-0.30 \\
-0.94 \text { to }-0.43\end{array}$ & $\begin{array}{l}-0.66 \\
-0.68\end{array}$ & $\begin{array}{l}-0.94 \text { to }-0.39 \\
-0.98 \text { to }-0.38\end{array}$ & 0.252 & 0.384 & 0.353 \\
\hline $\begin{array}{l}\text { Attention/working } \\
\text { memory } z \text {-score }\end{array}$ & $\begin{array}{l}\text { Dyslipidemia } \\
\text { No dyslipidemia }\end{array}$ & $\begin{array}{l}-0.25 \\
-0.29\end{array}$ & $\begin{array}{l}-0.49 \text { to }-0.01 \\
-0.55 \text { to }-0.04\end{array}$ & $\begin{array}{l}-0.40 \\
-0.30\end{array}$ & $\begin{array}{l}-0.67 \text { to }-0.12 \\
-0.59 \text { to } 0.00\end{array}$ & 0.693 & 0.266 & 0.273 \\
\hline $\begin{array}{l}\text { Executive function } \\
z \text {-score }\end{array}$ & $\begin{array}{l}\text { Dyslipidemia } \\
\text { No dyslipidemia }\end{array}$ & $\begin{array}{l}-0.49 \\
-0.63\end{array}$ & $\begin{array}{l}-0.73 \text { to }-0.25 \\
-0.88 \text { to }-0.37\end{array}$ & $\begin{array}{l}-0.65 \\
-0.60\end{array}$ & $\begin{array}{l}-0.93 \text { to }-0.38 \\
-0.89 \text { to }-0.30\end{array}$ & 0.552 & 0.322 & 0.153 \\
\hline $\begin{array}{l}\text { Memory and learning } \\
z \text {-score }\end{array}$ & $\begin{array}{l}\text { Dyslipidemia } \\
\text { No dyslipidemia }\end{array}$ & $\begin{array}{l}-0.43 \\
-0.46\end{array}$ & $\begin{array}{l}-0.68 \text { to }-0.19 \\
-0.71 \text { to }-0.20\end{array}$ & $\begin{array}{l}-0.64 \\
-0.35\end{array}$ & $\begin{array}{l}-0.92 \text { to }-0.36 \\
-0.65 \text { to }-0.05\end{array}$ & 0.060 & 0.459 & 0.022 \\
\hline
\end{tabular}

Estimates are adjusted for age, sex, education, APOE- $\varepsilon 4$, smoking, alcohol use, leisure time activity, depressive symptoms, cardiovascular disease and stroke, and other cardiometabolic risk factors as appropriate. Bold type denotes significance at $p<0.05$. MetS, metabolic syndrome; WC, waist circumference; BP, blood pressure.

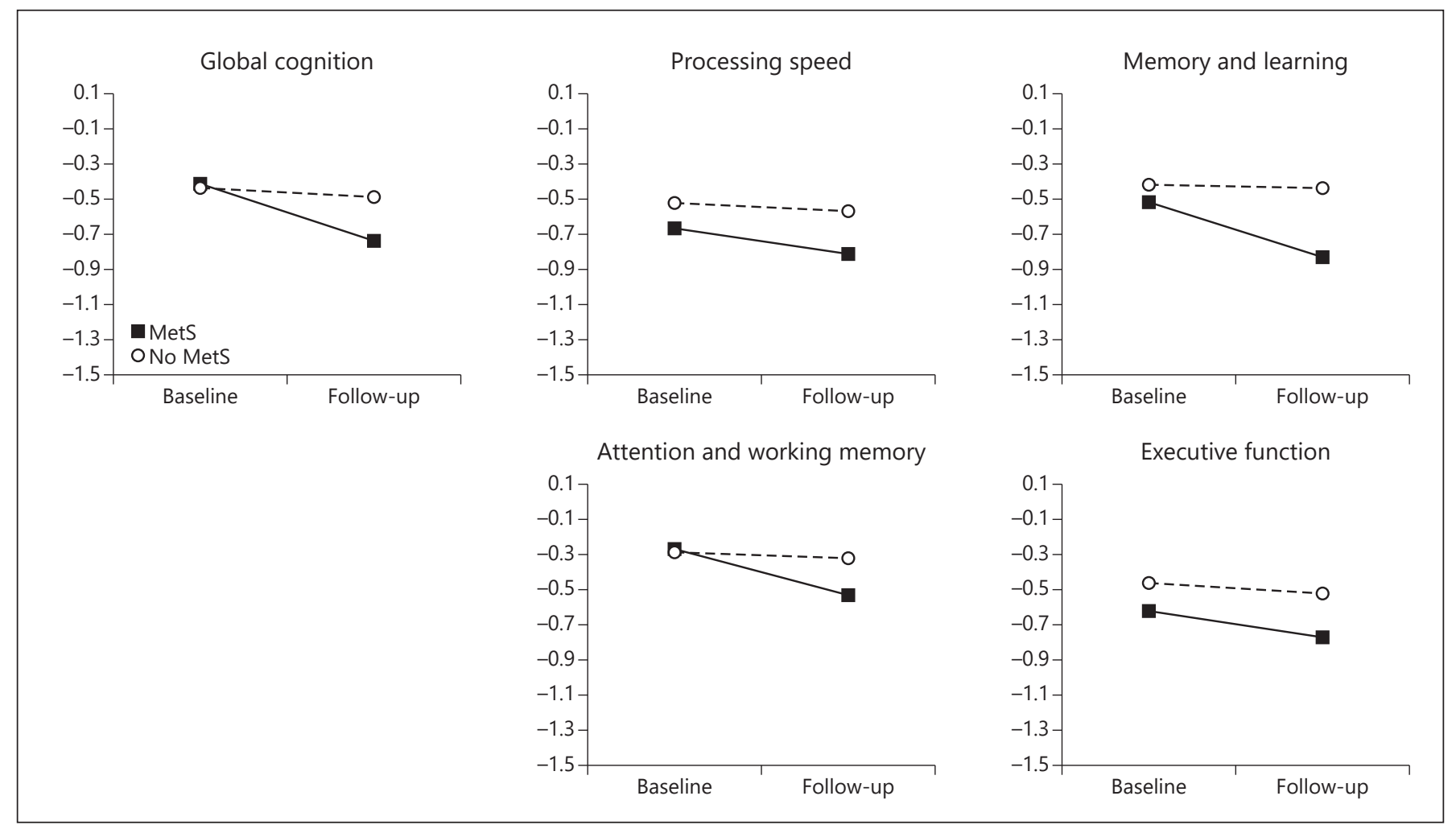

Fig. 1. Estimates of cognitive performance scores at baseline and follow-up associated with the MetS, adjusted for age, sex, education, APOE- $\varepsilon 4$, smoking, alcohol use, leisure time activity, depressive symptoms, cardiovascular disease and stroke. MetS, metabolic syndrome. 
Table 4. Adjusted estimates of cognitive performance scores at baseline and follow-up associated with the number of MetS components in mixed-model analyses

\begin{tabular}{|c|c|c|c|c|c|c|c|c|c|}
\hline \multirow[t]{2}{*}{ Cognitive scores } & \multicolumn{2}{|c|}{$\begin{array}{l}\text { Number of MetS } \\
\text { components }(0-5)\end{array}$} & \multicolumn{2}{|c|}{$\begin{array}{l}\text { Time } \\
\text { (follow-up vs. baseline) }\end{array}$} & \multicolumn{2}{|c|}{$\begin{array}{l}\text { Number of Mets } \\
\text { components } \times \text { time }\end{array}$} & \multicolumn{3}{|c|}{$\begin{array}{l}\text { Significance tests } \\
\text { ( } p \text { value) }\end{array}$} \\
\hline & estimate & $95 \% \mathrm{CI}$ & estimate & $95 \% \mathrm{CI}$ & estimate & $95 \% \mathrm{CI}$ & group & time & group $\times$ time \\
\hline Processing speed & -0.04 & -0.10 to 0.02 & 0.09 & -0.15 to 0.33 & -0.09 & -0.21 to 0.03 & 0.008 & 0.473 & 0.137 \\
\hline Attention/working memory & -0.01 & -0.07 to 0.05 & 0.12 & -0.12 to 0.36 & -0.12 & -0.24 to -0.01 & 0.025 & 0.312 & 0.039 \\
\hline Executive function & -0.05 & -0.11 to 0.01 & 0.06 & -0.18 to 0.29 & -0.08 & -0.20 to 0.04 & 0.004 & 0.647 & 0.186 \\
\hline Memory and learning & -0.02 & -0.08 to 0.04 & 0.18 & -0.06 to 0.42 & -0.15 & -0.27 to -0.03 & 0.002 & 0.142 & 0.011 \\
\hline Global & 0.01 & -0.08 to 0.10 & 0.11 & -0.14 to 0.36 & -0.14 & -0.26 to -0.01 & 0.065 & 0.377 & 0.032 \\
\hline
\end{tabular}

Estimates are adjusted for age, sex, education, APOE- $\varepsilon 4$, smoking, alcohol use, leisure time activity, depressive symptoms, cardiovascular disease and stroke. Bold type denotes significance at $p<0.05$. MetS, metabolic syndrome.

\section{Discussion}

In this population cohort of middle-aged and older persons without dementia, we found specific inverse cross-sectional associations of single cardiometabolic risk factors with cognition: central obesity with executive function; hyperglycemia with processing speed; and high blood pressure with processing speed, attention/working memory and executive function. Dyslipidemia, compared to no dyslipidemia, in particular was associated with significantly worse decline in memory and learning. These various cardiometabolic risk factors taken together as the MetS were significantly associated cross-sectionally with processing speed, executive function, and memory and learning. The count of cardiometabolic risk factors in the same individual was unambiguous in showing cross-sectional differences in all cognitive domains, as well as worse declines in attention and working memory, memory and learning, and global cognition. The impact of the MetS on cognitive decline was nontrivial, as the estimated effect of having $4 \mathrm{MetS}$ components was equivalent to an additional 14 years of age.

The weaknesses and limitations of previous studies, giving rise to vastly heterogeneous results, have been highlighted in a recent systematic review [9]. These included deviations in measurements for the diagnosis of the MetS, such as body mass index instead of waist circumference, and the use of abbreviated sets of cognitive tests or single screening tools such as the MMSE to evaluate cognition. In this study, the MetS was defined according to NCEP ATP III criteria, and a comprehensive protocol for neurocognitive assessment was used. A major source of heterogeneity of study results has been demonstrated to be the stratification effect of age [10]. Among studies of oldest-old persons ( $>75$ or 80 years old), the MetS was not found to be associated with cognitive decline, and in fact was suggested to have a "protective ef- fect" on the cognitive functioning of those subjects $[9,10$, 19-23], reinforcing the often observed paradoxical effect of established risk factors on cognitive (and other health) outcomes in the oldest-old. In contrast, our results are unambiguous when observed in a population of middleaged and older adults who are mostly younger than 75 years.

Our findings thus suggest that the individual small effects of single cardiometabolic risk factors are amplified when occurring together in the same individual as the MetS. The MetS showed a significant cross-sectional association with cognitive function, but not with worse cognitive decline over time. However, the number of cardiometabolic disorders present in the same individual was robustly associated with both cognitive function at baseline and worse cognitive function over time. Our results are very consistent with a previous study [18] suggesting that rather than the MetS status per se, the number of cardiometabolic disorders is associated with poorer cognitive function and decline.

A limitation of this study is that a reduced number of participants were assessed comprehensively on cognitive domain function at baseline and follow-up. At baseline, comprehensive neurocognitive domain measurements were selectively performed on a random one-in-three subsample of the follow-up cohort; hence, data were missing at random on this account. In the follow-up cohort, we used a linear mixed model for regression analysis, assuming that data were missing at random, which reduces bias from otherwise using complete data. Nevertheless, attrition may also be influenced by selective dropout and cause selection bias in the observation of results. The follow-up study cohort might have been selectively chosen at baseline as a survival cohort, and prevalence bias may explain the nonsignificant association of the MetS with baseline cognitive function. Compared to other cohort participants 
without comprehensive neurocognitive assessment, the participants in this study tended to be younger, and in better health and functioning. Individuals who were excluded from the analysis due to death $(n=227)$ and loss to follow-up ( $n=296)$ were significantly more likely to be older, male, smokers, and less physically and socially active and to have diabetes. Accordingly, it is possible that the effects of the MetS on cognitive function over time may be underestimated, but the extent of this is unknown.

Our study strongly implicates cardiometabolic disorders as a group of potentially treatable risk factors for cognitive impairment. Rather than the diagnosis of the MetS itself, the count of the number of cardiometabolic risk factors may be more useful in discriminating individuals at risk of cognitive decline and dementia. Further studies should investigate the possible usefulness of identifying the presence of cardiometabolic and vascular disorders to screen for risk of cognitive impairment and decline, and subsequent multidomain lifestyle and health behavioral interventions for dementia prevention.

Published in Celebration of the 30th Anniversary of the inception of Dementia and Geriatric Cognitive Disorders 1990-2020.

\section{Acknowledgments}

We thank the following voluntary welfare organizations for their support: Geylang East Home for the Aged, Presbyterian Community Services, St Luke's Eldercare Services, Thye Hua Kwan Moral Society (Moral Neighbourhood Links), Yuhua Neighbourhood Link, Henderson Senior Citizens' Home, NTUC Eldercare Co-op Ltd, Thong Kheng Seniors Activity Centre (Queenstown Centre) and Redhill Moral Seniors Activity Centre.

\section{Statement of Ethics}

The study was approved by the National University of Singapore Institutional Review Board. All participants gave written informed consent.

\section{Conflict of Interest Statement}

T.P.N. is an Editorial Board Member of Dementia and Geriatric Cognitive Disorders. P.M.P.-G., X.G., Q.G., D.Q.L.C. and J.F. declare that they have no affiliations with or involvement in any organization or entity with any financial interest (e.g., employment, consultancies, honoraria, stock ownership and options, expert testimony, grants or patents received or pending, royalties), or nonfinancial interest (such as personal, political, or professional relationships) that may potentially have influenced the writing of the manuscript.

\section{Funding Sources}

The study was supported by research grants from the Agency for Science Technology and Research (A*STAR) Biomedical Research Council (BMRC/08/1/21/19/567) and the National Medical Research Council (NMRC/1108/2007; NMRC/CIRG/1409/2014). The sponsors had no role in preparation of the data nor of the manuscript.

\section{Author Contributions}

P.M.P.-G. and T.P.N. reviewed the literature, and drafted and revised the manuscript; T.P.N. designed the study and analyzed the data; P.M.P.-G., Q.G., X.G., D.Q.L.C. and J.F. contributed to the study design and data collection; all authors reviewed the results and drafts, and approved the final manuscript.

\section{References}

1 Alberti KG, Eckel RH, Grundy SM, Zimmet PZ, Cleeman JI, Donato KA, et al.; International Diabetes Federation Task Force on Epidemiology and Prevention; National Heart, Lung, and Blood Institute; American Heart Association; World Heart Federation; International Atherosclerosis Society; International Association for the Study of Obesity. Harmonizing the metabolic syndrome: a joint interim statement of the International Diabetes Federation Task Force on Epidemiology and Prevention; National Heart, Lung, and Blood Institute; American Heart Association; World Heart Federation; International Atherosclerosis Society; and International Association for the Study of Obesity. Circulation. 2009 Oct;120(16):1640-5.
2 Mottillo S, Filion KB, Genest J, Joseph L, Pilote L, Poirier P, et al. The metabolic syndrome and cardiovascular risk a systematic review and meta-analysis. J Am Coll Cardiol. 2010 Sep;56(14):1113-32.

3 Shin JA, Lee JH, Lim SY, Ha HS, Kwon HS, Park YM, et al. Metabolic syndrome as a predictor of type 2 diabetes, and its clinical interpretations and usefulness. J Diabetes Investig. 2013 Jul;4(4):334-43.

4 Li X, Li X, Lin H, Fu X, Lin W, Li M, et al. Metabolic syndrome and stroke: a meta-analysis of prospective cohort studies. J Clin Neurosci. 2017 Jun;40:34-8.

5 Panza F, Frisardi V, Seripa D, Imbimbo BP, Sancarlo D, D'Onofrio G, et al. Metabolic syn- drome, mild cognitive impairment, and dementia. Curr Alzheimer Res. 2011 Aug;8(5): 492-509.

6 Atti AR, Valente S, Iodice A, Caramella I, Ferrari B, Albert U, et al. Metabolic syndrome, mild cognitive impairment, and dementia: a meta-analysis of longitudinal studies. Am J Geriatr Psychiatry. 2019 Jun; 27(6):625-37.

7 Pal K, Mukadam N, Petersen I, Cooper C. Mild cognitive impairment and progression to dementia in people with diabetes, prediabetes and metabolic syndrome: a systematic review and meta-analysis. Soc Psychiatry Psychiatr Epidemiol. 2018 Nov;53(11):114960. 
8 Ma F, Wu T, Zhao J, Ji L, Song A, Zhang M, et al. Prevalence of mild cognitive impairment and its subtypes among Chinese older adults: role of vascular risk factors. Dement Geriatr Cogn Disord. 2016;41(5-6):261-72.

9 Assuncao N, Sudo FK, Drummond C, de Felice FG, Mattos P. Metabolic syndrome and cognitive decline in the elderly: a systematic review. PLoS One. 2018 Mar;13(3):e0194990.

10 Siervo M, Harrison SL, Jagger C, Robinson L, Stephan BC. Metabolic syndrome and longitudinal changes in cognitive function: a systematic review and meta-analysis. J Alzheimers Dis. 2014;41(1):151-61.

11 McEvoy LK, Laughlin GA, Barrett-Connor E, Bergstrom J, Kritz-Silverstein D, Der-Martirosian C, et al. Metabolic syndrome and 16year cognitive decline in community-dwelling older adults. Ann Epidemiol. 2012 May; 22(5):310-7.

12 Viscogliosi G, Chiriac IM, Andreozzi P, Ettorre E. The metabolic syndrome predicts longitudinal changes in Clock Drawing Test performance in older nondemented hypertensive individuals. Am J Geriatr Psychiatry. 2016 May;24(5):359-63.

13 Yaffe K, Haan M, Blackwell T, Cherkasova E, Whitmer RA, West N. Metabolic syndrome and cognitive decline in elderly Latinos: findings from the Sacramento Area Latino Study of Aging study. J Am Geriatr Soc. 2007 May; 55(5):758-62.

14 Akbaraly TN, Kivimaki M, Shipley MJ, Tabak AG, Jokela M, Virtanen M, et al. Metabolic syndrome over 10 years and cognitive functioning in late midlife: the Whitehall II study. Diabetes Care. 2010 Jan;33(1):84-9.

15 Raffaitin C, Féart C, Le Goff M, Amieva H, Helmer C, Akbaraly TN, et al. Metabolic syndrome and cognitive decline in French elders: the Three-City Study. Neurology. 2011 Feb; 76(6):518-25.
16 Komulainen P, Lakka TA, Kivipelto M, Hassinen M, Helkala EL, Haapala I, et al. Metabolic syndrome and cognitive function: a population-based follow-up study in elderly women. Dement Geriatr Cogn Disord. 2007; 23(1):29-34.

17 Yaffe K, Kanaya A, Lindquist K, Simonsick EM, Harris T, Shorr RI, et al. The metabolic syndrome, inflammation, and risk of cognitive decline. JAMA. 2004 Nov;292(18):223742.

18 Kesse-Guyot E, Julia C, Andreeva V, Fezeu L, Hercberg S, Galan P. Evidence of a cumulative effect of cardiometabolic disorders at midlife and subsequent cognitive function. Age Ageing. $2015 \mathrm{Jul} ; 44(4): 648-54$.

19 Viscogliosi G, Donfrancesco C, Palmieri L, Giampaoli S. The metabolic syndrome and 10 year cognitive and functional decline in very old men. A population-based study. Arch Gerontol Geriatr. 2017 May-Jun;70:62-6.

20 van den Berg E, Biessels GJ, de Craen AJ, Gussekloo J, Westendorp RG. The metabolic syndrome is associated with decelerated cognitive decline in the oldest old. Neurology. 2007 Sep;69(10):979-85.

21 Harrison SL, Stephan BC, Siervo M, Granic A, Davies K, Wesnes KA, et al. Is there an association between metabolic syndrome and cognitive function in very old adults? The Newcastle 85+ Study. J Am Geriatr Soc. 2015 Apr;63(4):667-75.

22 Liu CL, Lin MH, Peng LN, Chen LK, Su CT, Liu LK, et al. Late-life metabolic syndrome prevents cognitive decline among older men aged 75 years and over: one-year prospective cohort study. J Nutr Health Aging. 2013; 17(6):523-6.
23 Katsumata Y, Todoriki H, Higashiuesato Y, Yasura S, Willcox DC, Ohya Y, et al. Metabolic syndrome and cognitive decline among the oldest old in Okinawa: in search of a mechanism. The KOCOA Project. J Gerontol A Biol Sci Med Sci. 2012 Feb;67(2): 126-34.

24 Dearborn JL, Knopman D, Sharrett AR, Schneider AL, Jack CR Jr, Coker LH, et al. The metabolic syndrome and cognitive decline in the Atherosclerosis Risk in Communities study (ARIC). Dement Geriatr Cogn Disord. 2014;38(5-6):337-46.

25 Muller M, Tang MX, Schupf N, Manly JJ, Mayeux R, Luchsinger JA. Metabolic syndrome and dementia risk in a multiethnic elderly cohort. Dement Geriatr Cogn Disord. 2007;24(3):185-92.

26 Mazza A, Pessina AC, Zamboni S, Casiglia E. Prognostic role of metabolic syndrome in the elderly is not greater than the sum of its components. Aging Health. 2010;6(2):217-28.

27 Ng TP, Feng L, Nyunt MS, Feng L, Gao Q, Lim ML, et al. Metabolic syndrome and the risk of mild cognitive impairment and progression to dementia: follow-up of the Singapore Longitudinal Ageing Study cohort. JAMA Neurol. 2016 Apr;73(4):456-63.

28 Lee CK, Collinson SL, Feng L, Ng TP. Preliminary normative neuropsychological data for an elderly chinese population. Clin Neuropsychol. 2012;26(2):321-34.

29 Niti M, Yap KB, Kua EH, Tan CH, Ng TP. Physical, social and productive leisure activities, cognitive decline and interaction with APOE-epsilon 4 genotype in Chinese older adults. Int Psychogeriatr. 2008 Apr;20(2): $237-51$ 